\title{
Profissão e carreira: Relações entre escolhas por cursos de graduação e âncoras de carreira
}

\author{
Profession and career: Relations between choices for undergraduate courses and career anchors
}

\author{
lúri Novaes Luna ${ }^{[0]}$, Mariana Michelena Santos ${ }^{[b]}$
}

\footnotetext{
[a] Doutor em Sociologia Política pela Universidade Federal de Santa Catarina (UFSC), Florianópolis, SC - Brasil, e-mail: iuri.luna@unisul.br

${ }^{[b]}$ Graduada em Psicologia pela Universidade do Sul de Santa Catarina (Unisul), Florianópolis, SC - Brasil, e-mail: mariana@marianamichelena.com.br
}

Recebido: 06/06/2011 Received: 06/06/2011

Aprovado: $14 / 11 / 2011$ Approved: 11/14/2011

\section{Resumo}

O estudo teve como objetivo principal caracterizar as relações existentes entre as âncoras de carreira de estudantes universitários e suas escolhas por cursos de graduação. Buscou-se verificar se pessoas que escolhem o mesmo curso superior compartilham âncoras de carreira semelhantes. Participaram da pesquisa 855 estudantes dos primeiros ou segundos semestres de 16 cursos de graduação de duas universidades, os quais responderam a um questionário composto por perguntas sobre dados biográficos e pelo Inventário de Orientação de Carreira, baseado nas âncoras de carreira indicadas por Edgar Schein. As informações coletadas foram submetidas à análise estatística descritiva e inferencial, mediante o teste qui-quadrado, com o intuito de verificar associações entre as variáveis investigadas. Os resultados apontaram associações significativas de nove cursos de graduação com determinadas âncoras de carreira, o que permite afirmar que, quando comparados aos demais alunos, os estudantes de tais cursos tendem a compartilhar aspirações específicas no que se refere à carreira profissional. Assim sendo, conclui-se que um número expressivo de sujeitos, ao escolherem determinada profissão de nível superior, provavelmente a associam a tipos específicos de carreira.

Palavras-chave: Escolha profissional. Âncoras de carreira. Ensino Superior.

\section{Abstract}

The main aim of this study was to characterize the existing relationship between the career anchors of college students and their choices for undergraduate courses. The research sought to investigate if people who choose the same undergraduate course tend to share similar career anchors. The researched population corresponded to 855 students from the first or second halves of 16 undergraduate courses at two universities, who answered a questionnaire with questions on biographical data and the Career Orientation Inventory, based on career anchors specified by Edgar Schein. The data were analyzed through descriptive and inferential statistics, using the chi-square statistic test, in order to examine associations between the variables investigated. The results showed significant associations of nine undergraduate courses with certain career anchors, which have shown that, when compared to other students, the students of such courses tend to share specific aspirations with regard to career. Therefore, it is possible to conclude that 
a significant number of subjects, when choosing a certain higher education profession, probably associate it with specific types of career

Keywords: Occupational choice. Career anchors. Higher education.

\section{Introdução}

$\mathrm{O}$ século XX foi marcado por significativas mudanças no que tange ao trabalho humano. A reestruturação econômica, associada aos avanços tecnológicos e à demanda por profissionais polivalentes e flexíveis, transformou as possibilidades de atuação profissional (Alves, 2007; Antunes, 2006; Aued, 2005), dando origem a novas profissões e campos de atuação no mercado de trabalho, ao mesmo tempo em que destituiu o sentido de necessidade de algumas profissões (Aued, 1997; Ferretti, 1997). Portanto, se em um passado não muito remoto existiam opções bem delimitadas e restritas de profissões e ocupações a serem desempenhadas pelos sujeitos, atualmente observa-se uma extensa gama de possibilidades cambiantes, o que torna o processo de escolha profissional mais complexo, sobretudo por este ocupar um lugar central na definição dos planos e estilos de vida (Giddens, 2002).

Por efetivar-se predominantemente na juventude, a decisão por uma profissão geralmente constitui-se como uma das primeiras escolhas de alta consequência (Giddens, 2002) realizada pelos indivíduos; muitas vezes, como a primeira decisão que tem resultados particulares fundamentais para suas vidas no futuro. Neste momento, os jovens são impelidos a refletirem e avaliarem possibilidades e necessidades, de acordo com suas oportunidades de vida. Alguns, por precisarem se inserir no mercado de trabalho, definem suas ocupações e profissões de forma antecipada (Bastos, 2005; Bock, 2006; Lisboa, 2002) e, frequentemente, acabam por abandonar os estudos - o que restringe suas possibilidades de carreira (Teles, Freguglia, \& Carvalho, 2002); outros veem-se confrontados a realizar a escolha profissional apenas na iminência da conclusão do Ensino Médio (Bock, 2006; Sparta \& Gomes, 2005).

Para atender a crescente demanda por profissionais mais qualificados, muitos jovens, após o Ensino Médio, buscam continuar seus estudos por meio do Ensino Superior (Prado, 1993; Sparta \& Gomes, 2005). Nesse sentido, Nunes e Carvalho
(2006) apontam que, no Brasil, o ensino universitário configura-se como um processo de profissionalização precoce, tendo em vista que as exigências de um mercado de trabalho complexo e rotativo - tais como falar e escrever bem, preparar bons relatórios, ter conhecimento de informática, possuir raciocínio lógico quantitativo, falar e ler uma segunda língua - ficam, com frequência, em segundo plano. Os autores evidenciam, ainda, o fato de que um grande contingente de graduados em cursos superiores não trabalha na área em que se formou.

Não obstante, o número de jovens que ingressa em instituições de ensino superior cresce anualmente. Programas governamentais como o Programa Universidade para Todos (ProUni), o Fundo de Financiamento ao Estudante do Ensino Superior (Fies) e o Exame Nacional do Ensino Médio (Enem), mediante bolsas de estudo e financiamentos, oportunizam que jovens de classes populares também frequentem universidades, tornando viável o projeto de exercer uma profissão de nível superior para um segmento maior da população brasileira.

Assim sendo, observa-se que a escolha profissional necessariamente envolve dimensões políticas (Hotza \& Lucchiari, 1998; Soares, 2002), econômicas (Bastos, 2005), sociais (Bock \& Aguiar, 1995; Lehman, 1995; Soares, 2002; Whitaker, 1997) e educacionais (Soares, 2002). Ademais, enredadas nas determinações macrossociais, destacam-se ainda as dimensões familiares (Bohoslavsky, 2007; Dias, 1995; Lehman, 1995; Lima \& Ramos, 2002; Levenfus \& Nunes, 2002; Lisboa, 2002; Porto \& Tamayo, 2006; Santos, 2005; Soares, 2002; Sobral, Gonçalves, \& Coimbra, 2009) e psicológicas (Bock, 2006; Silva \& Birck, 2002; Santos, 2005; Soares, 2002; Soares, 2007). Desse modo, o sistema familiar, a história pessoal e o projeto de vida, a autopercepção a respeito de valores, competências, motivos e interesses, bem como as representações sobre ocupações, profissões, áreas de atuação, exigências do mercado de trabalho e carreira explicam, em grande parte, o processo de escolha profissional de cada indivíduo. 
Destarte, a presente investigação possui como escopo o estudo dos valores, motivos e competências que orientam os indivíduos nos processos de escolha e desenvolvimento de carreira. Esse conjunto (valores, motivos e competências) do qual não se abre mão nos momentos de decisão profissional é denominado por Schein $(1978,1990,1996 b$, 2006a) como âncoras de carreira.

Fundamentando-se nesse conceito, o objetivo da pesquisa foi identificar as âncoras de carreira de estudantes universitários por meio da aplicação do Inventário de Orientação de Carreira (Schein, 1990), e as associar à escolha por determinados cursos de graduação. Especificamente, buscou-se identificar se pessoas que escolhem um mesmo curso compartilham âncoras de carreira semelhantes, tendo em vista a possibilidade da escolha por diferentes profissões estar associada a determinadas âncoras.

\section{Aporte teórico}

O conceito de âncoras de carreira advém de uma pesquisa longitudinal realizada com 44 alunos de um curso de mestrado (Schein, 1996b). No último ano do programa de pós-graduação os participantes responderam entrevistas e questionários acerca de seus valores e atitudes; e 12 anos após o término do curso foram novamente entrevistados. Nessas entrevistas, os participantes foram solicitados a identificar as escolhas e eventos fundamentais que permearam suas carreiras ao longo do tempo, assim como os motivos pelos quais haviam feito essas escolhas e os sentimentos relacionados às mudanças. Apesar da variedade de acontecimentos transcorridos nesse período de 12 anos, observou-se que tanto os motivos atribuídos pelos participantes para as suas escolhas quanto a forma como manifestaram seus sentimentos revelaram-se uniformes, resultando em um senso de identidade desenvolvido no aprendizado dos primeiros anos da vida profissional. Segundo os participantes da pesquisa, quando eles desviavam-se desse padrão de motivos e sentimentos em suas escolhas profissionais, eram "levados de volta" (Schein, 1996b, p. 36) a algo mais compatível com eles. Para ilustrar a tendência do indivíduo de retornar a algo que se ajustasse melhor às suas necessidades, Schein (1996b) utilizou a metáfora das "âncoras de carreira".
0 extenso estudo sobre âncoras de carreira desenvolvido por Edgar H. Schein e seus posteriores desdobramentos em pesquisas realizadas com profissionais que desempenhavam diferentes ocupações em diversos países, possibilitou a identificação de oito categorias de inclinações profissionais das quais os indivíduos não abrem mão em suas escolhas profissionais. Elas diferenciam-se no que se refere, por exemplo, aos tipos de trabalho priorizados, aos sistemas de remuneração, benefícios, promoções e à forma de reconhecimento preferida (Schein,1978). São elas:

Autonomia e independência: pessoas que prezam a manutenção de sua liberdade e buscam realizar atividades fundamentadas em suas próprias normas, dentro de seu ritmo e de acordo com os próprios padrões, pelo fato de não estarem dispostas a se sujeitar a regras impostas por organizações de trabalho, por exemplo.

Segurança e estabilidade: sujeitos que priorizam segurança financeira e estabilidade no vínculo empregatício, assim como valorizam benefícios e boas condições de aposentadoria.

Competência técnico-funcional: pessoas que se motivam pelo exercício de suas aptidões em determinado tipo de trabalho e satisfazem-se ao saber que são peritos no que realizam. Promoções que afastem essas pessoas de suas especialidades como, por exemplo, para cargos de gerência geral ou supervisão, não são desejadas por esses sujeitos.

Competência administrativa geral: pessoas que valorizam subir degraus hierárquicos nas organizações com a finalidade de alcançar níveis mais elevados de responsabilidade e liderança e de receber altos rendimentos. Devem possuir capacidades integradoras, tais como facilidade no relacionamento interpessoal, capacidade analítica e equilíbrio emocional.

Criatividade empreendedora: sujeitos motivados em criar algo novo. Valorizam atividades nas quais possam expressar sua criatividade, entediando-se facilmente quando essa possibilidade não é viabilizada.

Dedicação a uma causa: pessoas que priorizam profissões nas quais possam incorporar seus valores, baseando-se no desejo de "melhorar o mundo" de alguma forma. Valorizam atividades que lhes permitam trabalhar com pessoas e exercitar capacidades interpessoais.

Desafio puro: pessoas competitivas que valorizam transpor obstáculos e solucionar problemas. 
Para elas, o sucesso está diretamente relacionado à resolução de questões aparentemente insolúveis ou à possibilidade de vencer oponentes.

Estilo de vida: indivíduos que priorizam integrar suas carreiras com suas necessidades individuais, familiares e sociais. Para que essa integração possa ser viabilizada nos diversos patamares de sua vida, valorizam flexibilidade no trabalho acima de tudo. Muitas vezes, apresentam relutância para mudanças geográficas em virtude da dificuldade de conciliar suas diferentes necessidades.

As pesquisas de Schein (1996b) possibilitaram constatar que cada pessoa identifica-se em graus variados com cada uma das categorias propostas como âncoras de carreira, assim como que algumas ocupações podem satisfazer necessidades de mais de uma dessas categorias. Entretanto, a singularidade de cada âncora é garantida pelo fato de que a autopercepção do sujeito a respeito de seus valores, competências e motivos possibilita a identificação dos interesses que estão no topo de uma hierarquia pessoal, estabelecendo a definição de uma âncora de carreira prioritária para cada sujeito. 0 autor observa, ainda, que a âncora de um indivíduo não costuma se modificar ao longo de sua carreira, pois no momento em que ele forma um autoconceito, este tende a permanecer estável, salvo em situações que provoquem mudanças significativas em sua vida (Schein, 2006a).

Desse modo, por meio da presente investigação, ou seja, da identificação das âncoras de carreira de estudantes universitários, torna-se possível verificar se determinados valores, motivos e competências associam-se a diferentes cursos de graduação; por exemplo, se indivíduos que cursam Enfermagem tendem a dedicar-se a uma causa e trabalhar com pessoas, enquanto que estudantes que escolheram Administração tendem a ser mais empreendedores e criativos ou a galgar escalões hierárquicos nas organizações. Nesse sentido, os resultados oferecem subsídios para uma compreensão mais precisa da força que a associação, idealizada pelos indivíduos, entre profissões e carreiras pode exercer no processo de escolha profissional.

Millan et al. (2005), em um estudo que objetivava determinar as razões da escolha da profissão médica por um grupo de alunos do curso de medicina de uma faculdade de São Paulo, observaram que os estudantes apresentaram perfis semelhantes quanto às motivações para a escolha da profissão e em relação ao perfil socioeconômico. Dentre os resultados da pesquisa, os autores identificaram que os alunos de medicina compartilham um desejo comum de ajudar os semelhantes e ser reconhecidos por isso.

Peñaloza, Diógenes e Sousa (2008), mediante uma investigação com alunos do curso de Administração, também verificaram a existência de perfis similares entre alunos que escolhem um mesmo curso. A pesquisa, com intuito de relacionar o empreendedorismo feminino com as razões da opção pelo curso de Administração, possibilitou identificar que os alunos que optam por esse curso, independentemente do gênero, já trazem consigo a ideia de serem empreendedores no momento em que ingressam na faculdade.

Tais pesquisas, embora não utilizem o conceito de âncoras de carreira, estudam perfis relacionados a profissões e carreiras muito semelhantes às âncoras definidas por Schein (1996b). Reforçam, assim, o pressuposto de que há associações entre a escolha por cursos de graduação e determinados valores, motivos e competências.

Existem, ainda, investigações que utilizam o conceito de âncoras de carreira para estudar o processo de escolha profissional, especificamente na graduação e na pós-graduação em Administração. Ferraz, Galli e Trevisan (2008) identificaram âncoras de carreira similares entre estudantes do mesmo sexo que cursam Administração. No que se refere aos homens, a âncora predominante foi "criatividade empreendedora", enquanto que, entre as mulheres, prevaleceu a âncora "estilo de vida". A respeito das âncoras de carreira que menos se destacaram, identificou-se, em estudantes de ambos os sexos, "dedicação a uma causa" e "segurança e estabilidade". Correia, Oliveira e Kilimnik (2006), em uma pesquisa realizada com mestrandos do curso de Administração de uma universidade de Minas Gerais, concluíram que a maioria dos entrevistados apresenta âncoras de carreira similares, tais como "estilo de vida", "autonomia" e "desafio puro".

Não obstante, pelo fato de as âncoras definidas por Schein constituírem-se como referenciais de carreira, a maioria dos estudos que abordam essa temática a relacionam com as decisões subsequentes ao processo inicial de escolha por uma profissão (Abrahim, 2008; Alberto, 2008; Chang, Hwang, Liu, \& Siang, 2007; Correia, Oliveira, \& Kilimnik, 2006; Faro, 2007; Ferraz, Galli, \& Trevisan, 2008; Kilimnik, Sant'anna, Oliveira, \& Barros, 2008; Kilimnik, Sant'anna, \& Castilho, 2008; Knabem, 
2005; Messara, Mourad, \& Harake, 2009; Rodrigues, Ferraz, \& Duarte, 2008; Rodrigues, Bouzada, \& Kilimnik, 2007; Sombrio, 2003). Assim sendo, observa-se a relevância, sobretudo para a área da escolha e orientação profissional, do desenvolvimento de estudos que pretendem identificar a relação entre as âncoras de carreira (valores, motivos e competências) e a escolha por determinados cursos de graduação, como objetiva a presente pesquisa.

\section{Método}

\section{Participantes}

Por se tratar de uma pesquisa descritiva delineada como uma survey (Gil, 1999), participaram do estudo 855 alunos de ambos os sexos, do primeiro ou segundo semestre de 16 cursos de graduação, ofertados simultaneamente em duas universidades localizadas na região da Grande Florianópolis, Santa Catarina, sendo uma pública e outra privada. Deu-se prioridade em interrogar alunos do primeiro semestre dos cursos selecionados (ingressantes). Entretanto, em virtude de alguns cursos não ofertarem turmas para ingressantes no período em que o estudo foi realizado, foram considerados sujeitos da pesquisa os alunos que cursavam o segundo semestre. As características sociodemográficas dos estudantes que participaram do estudo encontram-se na Tabela 1.

\section{Material}

O instrumento utilizado na coleta de dados foi composto: a) por um questionário elaborado pelos autores, que visava obter dados biográficos a respeito dos participantes da pesquisa, tais como sexo, idade, tempo de trabalho, principais atividades de trabalho realizadas, curso de graduação que está realizando e prioridade da escolha (se este curso constitui-se a primeira opção de escolha do sujeito); b) pelo Inventário de Orientação de Carreira (Career Orientations Inventory), baseado nas âncoras de carreira indicadas por Schein (1990).

O Inventário consiste em uma escala de classificação composta por 40 afirmativas, cujas respostas são graduadas em conformidade com o nível de concordância do sujeito. Origina-se de uma adaptação da escala Likert, na qual o respondente deve atribuir valor de 1 (um) a 6 (seis), sendo que o número 1 representa o maior grau de discordância com a afirmação exposta ("Jamais se aplica a você"), enquanto que o número 6 denota o maior grau de concordância com a afirmação exposta ("Sempre se aplica a você"). As afirmativas compreendem indicadores das oito categorias de âncoras de carreira, distribuídos de forma equitativa (cinco afirmativas para cada âncora). 0 valor final atribuído pelo indivíduo às âncoras corresponde ao somatório dos números indicados para cada uma das afirmativas. Desse modo, define-se a âncora de carreira predominante dos respondentes, ou seja, a que possui o maior valor entre as oito avaliadas.

\section{Procedimentos}

A coleta de dados foi realizada por turma, mediante aplicação coletiva do instrumento em horário de aula previamente cedido pelo professor. Todos os alunos que se encontravam em sala de aula no momento da aplicação foram convidados a participar do estudo. Antes dos estudantes responderem a pesquisa, eles foram orientados a respeito da participação voluntária e do sigilo em relação às informações coletadas. Pelo fato de o instrumento de coleta de dados constituir-se como um questionário anônimo, não foi necessário utilizar um termo de consentimento livre e esclarecido para a viabilização da coleta de informações, conforme indicação do Manual Operacional para Comitês de Ética em Pesquisa (Ministério da Saúde, 2002).

As informações obtidas foram tabuladas, formando um banco de dados, e submetidas à estatística descritiva, visto que se pretendeu apresentá-las e descrevê-las, e à análise inferencial, na medida em que se buscou verificar hipóteses. Para a análise foi utilizado o teste estatístico qui-quadrado $\left(\chi^{2}\right)$, o qual permite verificar a significância da associação entre duas variáveis qualitativas (Barbetta, 2002).

\section{Resultados}

Os resultados obtidos por meio do Inventário de Orientação de Carreira possibilitaram identificar as âncoras de carreira que predominam entre os alunos de cada um dos 16 cursos investigados, 
Tabela 1 - Características sociodemográficas dos participantes do estudo de acordo com as categorias sexo, idade, experiência profissional, tempo total de trabalho e curso $(n=855)$

\begin{tabular}{|c|c|c|}
\hline Categoria & Variável & Frequência \\
\hline \multirow{2}{*}{ Sexo } & Feminino & 486 \\
\hline & Masculino & 369 \\
\hline \multirow{5}{*}{ Idade } & $17-20$ & 573 \\
\hline & $21-25$ & 169 \\
\hline & $26-30$ & 70 \\
\hline & $>30$ & 42 \\
\hline & Não respondeu & 1 \\
\hline \multirow{3}{*}{$\begin{array}{l}\text { Experiência } \\
\text { profissional }\end{array}$} & Trabalha ou já traba- & 539 \\
\hline & Nunca trabalhou & 314 \\
\hline & Não respondeu & 2 \\
\hline \multirow{4}{*}{$\begin{array}{l}\text { Tempo total de } \\
\text { trabalho }\end{array}$} & $\leq 5$ anos & 387 \\
\hline & $6-10$ anos & 83 \\
\hline & $>10$ anos & 62 \\
\hline & Não respondeu & 7 \\
\hline \multirow{16}{*}{ Curso } & Administração & 67 \\
\hline & Arquitetura & 70 \\
\hline & Ciências da Computação & 59 \\
\hline & Cinema & 29 \\
\hline & Direito & 103 \\
\hline & Educação Física & 50 \\
\hline & Enfermagem & 38 \\
\hline & Engenharia Civil & 90 \\
\hline & Jornalismo & 34 \\
\hline & Letras Português & 23 \\
\hline & Matemática & 30 \\
\hline & Medicina & 78 \\
\hline & Pedagogia & 39 \\
\hline & Psicologia & 56 \\
\hline & Relações Internacionais & 50 \\
\hline & Serviço Social & 39 \\
\hline
\end{tabular}

Fonte: Dados da pesquisa.

assim como as que menos se destacaram. Desse modo, observa-se que apenas quatro (dedicação a uma causa; estilo de vida; desafio puro; autonomia e independência) das oito âncoras estudadas situaram-se em primeiro lugar. Enquanto uma (dedicação a uma causa) prevaleceu em 11 cursos, outras (segurança e estabilidade; criatividade empreendedora; competência técnico-funcional; competência administrativa geral) não apareceram com maior frequência em nenhum dos cursos pesquisados.

A âncora "dedicação a uma causa" foi identificada como predominante entre os alunos dos cursos de Medicina (63\%), Enfermagem (60\%), Serviço Social (56\%), Psicologia (50\%), Pedagogia (46\%), Educação Física (40\%), Jornalismo (38\%), Matemática (33\%), Letras Português (30\%), Relações Internacionais (28\%) e Direito (27\%). De fato, tendo em vista as oito âncoras, "dedicação a uma causa" se destacou de forma significativa, uma vez que aproximadamente um terço (261 alunos) dos 855 participantes da pesquisa possui essa âncora de carreira em evidência.

A âncora "estilo de vida" foi a segunda mais presente, pois apareceu com maior frequência entre os estudantes de quatro dos 16 cursos pesquisados, sendo eles: Arquitetura (31\%), Letras Português (30\%), Engenharia Civil (29\%) e Administração (24\%). Concentrou aproximadamente 20\% (173 alunos) do total de sujeitos investigados. Observa-se que no curso de Letras Português houve um empate entre as âncoras que mais se destacaram, sendo elas "dedicação a uma causa" e "estilo de vida".

Na sequência, a âncora de carreira identificada com frequência elevada entre os sujeitos investigados foi "desafio puro", sendo a âncora predominante de 135 estudantes. Entretanto, tal âncora apareceu com primazia em apenas um curso, Ciências da Computação (29\%). Por fim, a âncora "autonomia e independência", sendo a predominante de apenas 73 estudantes, ocupou o primeiro lugar entre os alunos do curso de Cinema (24\%).

No que tange às âncoras que apareceram com menor frequência, as que menos se destacaram foram "competência administrativa geral" e "competência técnico-funcional”, sendo identificadas, respectivamente, em apenas $1,2 \%$ e $5 \%$ dos estudantes investigados.

Quanto à força da relação entre as âncoras de carreira e os cursos de graduação, mediante o teste qui-quadrado foi possível observar associações estatisticamente significativas $(p \leq 0,05)$ entre nove cursos de graduação e determinadas âncoras de carreira. Conforme a Tabela 2, existem associações significativas entre os cursos de Medicina, Enfermagem, Serviço Social, Psicologia e Pedagogia e a âncora "dedicação a uma causa"; entre os cursos de Arquitetura e Engenharia Civil e a âncora "estilo de vida"; entre o curso de Ciências da Computação e a âncora "desafio puro"; entre o curso de Cinema e a âncora "autonomia e independência". 
Tabela 2 - Testes qui-quadrado e valores de $p$ para as âncoras de carreira que foram apresentadas com maior frequência em cada curso investigado

\begin{tabular}{llcc}
\hline $\begin{array}{l}\text { Âncora de } \\
\text { carreira }\end{array}$ & Curso & $\chi^{2}$ & $p$ \\
\hline & Medicina & 42,21 & 0,000 \\
& Enfermagem & 16,88 & 0,000 \\
& Serviço Social & 12,91 & 0,000 \\
& Psicologia & 10,71 & 0,001 \\
Dedicação a & Pedagogia & 4,71 & 0,030 \\
uma causa & Educação Física & 1,34 & 0,237 \\
& Jornalismo & 0,99 & 0,319 \\
& Direito & 0,62 & 0,432 \\
& Relações Internacionais & 0,16 & 0,689 \\
& Matemática & 0,12 & 0,734 \\
Estilo de & Letras Português & 0,00 & 0,992 \\
vida & Arquitetura & 5,92 & 0,015 \\
& Letras Português & 4,67 & 0,031 \\
Administração & 1,52 & 0,217 \\
Desafio & Ciências da Computação & 6,60 & 0,439 \\
puro & & & \\
Autonomia & & & \\
e indepen- & Cinema & & \\
dência & & 9,013 \\
\hline
\end{tabular}

Fonte: Dados da pesquisa.

\section{Discussão}

As relações estatisticamente significativas indicadas pelo teste qui-quadrado permitem afirmar que, quando comparados ao conjunto dos alunos investigados, os estudantes de determinados cursos tendem a compartilhar âncoras específicas no que se refere à carreira profissional. Assim sendo, reforça-se o pressuposto de que alguns estudantes, ao escolherem determinado curso de graduação, podem ter o associado a tipos específicos de carreira.

A análise dos dados coletados neste estudo possibilitou identificar similaridades entre os resultados desta pesquisa e os obtidos por Schein (1978, 1990, 1996a, 1996b, 2006a, 2006b, 2006c) em suas investigações sobre âncoras de carreira. 0 elevado índice de alunos que se identificou com a âncora "dedicação a uma causa" vai ao encontro das constatações do autor, quando ele afirma que é crescente o número de jovens e adultos que relatam estar sentindo a necessidade de fazer algo significativo em um contexto maior e não apenas manter um rendimento adequado no que tange à carreira profissional (Schein, 1996a).

Também foi possível observar que a maioria dos alunos que apresentaram a âncora "dedicação a uma causa" $(64,3 \%)$ é proveniente de cursos relacionados às profissões que envolvem auxílio aos semelhantes, tais como Medicina, Enfermagem, Serviço Social, Pedagogia, Psicologia e Direito. Nessa direção, Schein (1996b) afirma que aqueles que escolhem profissões relacionadas à assistência ao próximo, tais como Medicina, Enfermagem, Direito, trabalho social, ensino ou sacerdócio, costumam ter esse tipo de ponto de referência.

A elevada frequência da âncora "estilo de vida", que apareceu em segundo lugar entre as âncoras que mais se destacaram na investigação e se caracteriza pelo interesse em integrar necessidades individuais, familiares e da carreira, também reflete, segundo Schein (2006c), algumas tendências atuais da sociedade, tais como o crescente número de famílias em que os dois cônjuges têm suas respectivas carreiras. Para o autor, o balanceamento da vida pessoal e profissional sempre foi uma questão importante. Entretanto, em famílias em que apenas um cônjuge possui perspectivas de carreira, uma solução comum era, e continua sendo, a carreira deste dominar a situação familiar. Todavia, quando ambos os cônjuges têm interesse em desenvolver suas carreiras, o balanceamento do processo torna-se mais complexo, requerendo decisões econômicas, geográficas e outras que envolvem o estilo de vida familiar. Nesse sentido, chama a atenção o fato de a âncora "estilo de vida" ter apresentado associação significativa com os cursos de Arquitetura e Engenharia Civil, sendo o último tradicionalmente frequentado por homens.

O fato de a âncora "desafio puro", predominante entre os alunos do curso Ciências da Computação, ser a terceira que mais se destacou, relaciona-se, possivelmente, com as tendências do mundo do trabalho na contemporaneidade. Tal âncora é característica das pessoas que valorizam transpor desafios aparentemente insolúveis (Schein, 2006b). Esses desafios podem se materializar na busca por trabalhos em que situações cada vez mais difíceis possam ser enfrentadas, em termos interpessoais e competitivos. Para Schein (1996a), o número de pessoas ancoradas em "desafio puro" está em ascendência, visto que no mundo corporativo é crescente a 
quantidade de obstáculos a serem transpostos; sobretudo em um cenário marcado por intensas mudanças, instabilidade e falta de garantias (Antunes, 2006; Sennett, 2002; Bauman, 2001).

A âncora "autonomia e independência", identificada como predominante no curso de Cinema, reflete, por sua vez, os interesses de pessoas que valorizam fazer as coisas do seu modo, dentro do seu ritmo e de acordo com seus próprios padrões. Tais indivíduos buscam realizar suas atividades de trabalho fundamentados em suas próprias normas, pelo fato de não estarem dispostos a se sujeitarem a regras organizacionais. Essa é uma tendência dos sujeitos que desejam trabalhar como profissionais liberais (Schein, 1996b).

As âncoras "segurança e estabilidade", "criatividade empreendedora", "competência técnico-funcional" e "competência administrativa geral" não se destacaram em nenhum dos cursos investigados, sendo que esta última apontou a menor frequência entre todos os participantes da pesquisa, como já indicado. De acordo com Schein (1996b), a âncora "competência administrativa geral", por envolver o desenvolvimento de competências analíticas e emocionais, bem como de habilidades interpessoais, normalmente é estabelecida por meio da prática profissional. Nesse aspecto, a falta de identificação dos alunos investigados com a âncora em questão pode ter relação com o fato de a maioria deles encontrar-se no início de sua trajetória de trabalho ou, mesmo, nunca ter exercitado atividades profissionais. Desse modo, ainda não teriam tido experiências suficientes para desenvolver as competências requeridas para cargos de liderança nas organizações.

Assim como a reduzida frequência com que apareceu a âncora "competência administrativa geral" pode estar relacionada ao fato de $87 \%$ dos participantes da pesquisa ter, no máximo, 25 anos, o predomínio de sujeitos com âncoras "dedicação a uma causa" e "estilo de vida" também pode estar associado a esse fator. Soares (2002) aponta que muitos jovens mostram-se idealistas no período da escolha de uma profissão, sentindo-se poderosos e imaginando que realizarão feitos que vão modificar o mundo e melhorar a sociedade. Para quem depende economicamente dos pais ou responsáveis e não possui cônjuges ou filhos, é possível projetar com mais confiança a compatilibilização entre os valores pessoais e o futuro exercício profissional.
Entretanto, posteriormente, situações concretas da vida podem dificultar a busca por uma situação de trabalho idealizada e contribuir para o desenvolvimento de novas âncoras de carreira.

\section{Considerações finais}

Inicialmente, destaca-se que os resultados obtidos a respeito das âncoras de carreira apresentadas pelos estudantes investigados devem ser compreendidos respeitando-se determinados limites. Não obstante o fato de as âncoras apresentarem-se relativamente estáveis ao longo da vida dos indivíduos (Schein, 1990, 1996b, 2006c), observa-se que grande parte dos alunos investigados nunca trabalhou (37\%) ou encontra-se no início de sua trajetória de trabalho (45\%), o que suscita a possibilidade de eles ainda não possuírem interesses profissionais bem estabelecidos. Mesmo para aqueles que já trabalham há mais de dez anos (7\%), tempo suficiente para que o sujeito possua conhecimento para uma clara delimitação das âncoras de carreira (Schein, 1996b), o momento de ingresso em uma universidade muitas vezes se configura como uma situação de mudança significativa na vida, o que pode proporcionar o desenvolvimento de novas âncoras (Schein, 2006a).

Assim sendo, as âncoras e as associações identificadas neste estudo devem ser compreendidas em um determinado recorte de tempo e de acordo com as características sociodemográficas da população investigada, não cabendo generalizações e previsões categóricas, sobretudo para sujeitos que não se encontrem em situações semelhantes às dos participantes desta investigação.

As relações estatisticamente significativas identificadas entre nove cursos de graduação e certas âncoras de carreira indicam que alguns estudantes, ao escolherem determinado curso superior, podem tê-lo associado a um tipo específico de carreira. A decisão por uma profissão fundamentada na possibilidade de uma trajetória profissional que contemple determinados valores, motivos e competências (âncoras de carreira) pode significar que o estudante possui conhecimentos que permitem a realização de uma escolha consistente. Todavia, a escolha profissional atrelada à idealização de uma carreira específica pode refletir, também, uma imagem estereotipada de determinadas profissões e carreiras, 0 
que explicaria, em parte, a grande desigualdade na distribuição da procura por cursos superiores, bem como o acúmulo de indivíduos que compartilham âncoras semelhantes em certos cursos, em detrimento de outros.

Desse modo, a identificação de perfis semelhantes em determinados cursos de graduação, mediante a associação destes com as âncoras de carreira, configura-se como subsídio para intervenções em orientação profissional e planejamento de carreira. Possíveis distorções no que se refere às imagens das profissões podem ser problematizadas, bem como pode ser estimulado o autoconhecimento do sujeito a respeito de seus valores, competências e motivos, favorecendo, assim, escolhas profissionais mais consistentes.

Visto que esta investigação identificou, em uma perspectiva transversal, as âncoras de carreira de sujeitos que se encontravam no início de seus respectivos cursos, sugere-se que pesquisas longitudinais sejam realizadas para identificar se as âncoras tendem a permanecer estáveis durante as trajetórias acadêmicas dos estudantes ou se modificam. Estudos que expandissem o número de cursos selecionados também poderiam contribuir para a identificação de novas relações entre âncoras de carreira e cursos de graduação.

\section{Referências}

Abrahim, G. S. (2008). A influência dos valores humanos na determinação das âncoras de carreira. Dissertação de mestrado, Pontifícia Universidade Católica de São Paulo, São Paulo.

Alberto, D. G. (2008). O alinhamento das âncoras de carreira: Explorando a satisfação com o trabalho. Dissertação de mestrado, Pontifícia Universidade Católica de São Paulo, São Paulo.

Alves, G. (2007). Dimensões da reestruturação produtiva: Ensaios de sociologia do trabalho. Londrina: Praxis.

Antunes, R. (2006). A era da informatização e a época da informalização: riqueza e miséria do trabalho no Brasil. In R. Antunes (Org.). Riqueza e miséria do trabalho no Brasil. São Paulo: Boitempo Editorial.

Aued, B. W. (1997). Profissões no passado - profissões no futuro. Revista de Ciências Humanas, 15(22), 7-22.
Aued, B. W. (2005). Mudanças no mundo do trabalho: trajetórias profissionais em vias de desaparecimento e desemprego. In M. C. P. Lassance, A. C. Paradiso, M. P. Bardagi, M. Sparta \& S. L. Frischenbruder (Org.), Intervenção e Compromisso Social: Orientação profissional: teoria e técnica. São Paulo: Vetor.

Barbetta, P. A. (2002). Estatística aplicada às ciências sociais (5. ed.). Florianópolis: Editora da UFSC.

Bastos, J. C. (2005). Efetivação de escolhas profissionais de jovens oriundos do ensino público: um olhar sobre suas trajetórias. Revista Brasileira de Orientação Profissional, 6(1), 31-43. Recuperado em 15 de março, 2010, de http://pepsic.homolog.bvsalud.org/scielo. php?pid=S1679-33902005000200004\&script $=$ sci_ arttext

Bauman, Z. (2001). Modernidade líquida. Rio de Janeiro: Jorge Zahar Editora.

Bock, A. M. B., \& Aguiar, W. M. J. (1995). Por uma prática promotora de saúde em Orientação Vocacional. In A. M. B. Bock (Org.). A escolha profissional em questão. São Paulo: Casa do Psicólogo.

Bock, S. D. (2006). Orientação profissional: A abordagem sócio-histórica (3. ed.). São Paulo: Cortez.

Bohoslavsky, R. (2007). Orientação vocacional: A estratégia clínica (12. ed.). São Paulo: Martins Fontes.

Ministério da Saúde (2002). Manual Operacional para Comitês de Ética em Pesquisa. Brasília: Ministério da Saúde.

Chang, I., Hwang, H., Liu, C., \& Siang, S. (2007). A study of career anchors and job characteristic preferences of IS students. Journal of computer information systems, 47(3), 24-33. Recuperado em 2 de abril, 2010, de http://direct.bl.uk/bld/PlaceOrder.do?UIN=2083 31873\&ETOC=RN\&from=searchengine

Correia, C. M. S., Oliveira, J. A. C. K., \& Kilimnik, Z. M. (2006). Transição da carreira profissional para a acadêmica: um estudo com profissionais mestrandos de uma universidade privada de Minas Gerais. Anais eletrônicos da Reunião Anual da SBPC, Florianópolis, Santa Catarina, Brasil, 58. Recuperado em 14 de abril, 2010, de http://www.sbpcnet.org.br/livro/58ra/ SENIOR/RESUMOS/resumo_1351.html 
Dias, M. L. (1995). Família e escolha profissional. In A. M. B. Bock (Org.). A escolha profissional em questão. São Paulo: Casa do Psicólogo.

Faro, E. S. C. (2007). Âncoras de carreira e o modelo de administração gerencial: Um estudo de caso do Tribunal de Contas da União. Dissertação de mestrado, Pontifícia Universidade Católica de São Paulo, São Paulo.

Ferraz, I., Galli, D., \& Trevisan, L. (2008). Âncoras de carreira: uma questão de gênero? Revista Administração em Diálogo, 2(11), 90-117. Recuperado em 15 de abril, 2010, de http://revistas.pucsp.br/index.php/ $\mathrm{rad} /$ article/view/2713/1762

Ferretti, C. J. (1997). Uma nova proposta de orientação profissional (3. ed.). São Paulo: Cortez.

Giddens, A. (2002). Modernidade e identidade. Rio de Janeiro: Jorge Zahar Editora.

Gil, A. C. (1999). Métodos e técnicas de pesquisa social (5. ed.). São Paulo: Atlas.

Hotza, M. A. S., \& Lucchiari, D. H. P. S. (1998). A re-escolha profissional dos vestibulandos da UFSC de 1997. Revista da ABOP, 2(1), 97-110. Recuperado em 29 de março 2010, de http://pepsic.bvs-psi.org.br/pdf/rabop/v2n1/v2n1a06.pdf

Kilimnik, Z. M., Sant'anna, A. S., \& Castilho, I. V. (2008). Carreiras em transformação e seus paradoxais reflexos nos indivíduos: pesquisa de metáforas e âncoras de carreira, associada à representação de competências profissionais. Revista Eletrônica Gestão e Sociedade, 2(3). Recuperado em 10 de maio 2010, de http://www.face.ufmg.br/revista/index.php/ gestaoesociedade/article/viewFile/543/522

Kilimnik, Z. M., Sant'anna, A. S., Oliveira, L. C. V., \& Barros D. T. R. (2008). Seriam as âncoras de carreiras estáveis ou mutantes? - Um estudo com profissionais de Administração em transição de carreira. Revista Brasileira de Orientação Profissional, 9(1), 43-60. Recuperado em 29 de março, 2010, de http://pepsic.bvs-psi.org.br/scielo.php?script=sci_ arttext\&pid=S1679-33902008000100005\&lng=pt\& nrm=iso

Knabem, A. (2005). Trajetória profissional e âncoras de carreira de Edgar Schein: traçando possíveis relações. Dissertação de mestrado, Universidade Federal de Santa Catarina, Florianópolis, 2005.
Lehman, Y. P. (1995). O papel do orientador profissional: revisão crítica. In A. M. B. Bock (Org.). A escolha profissional em questão. São Paulo: Casa do Psicólogo.

Levenfus, R. S., \& Nunes, M. L. T. (2002). Principais temas abordados por jovens centrados na escolha profissional. In R. S. Levenfus \& D. H. P. Soares, Orientação vocacional ocupacional: novos achados teóricos, técnicos e instrumentais para a clínica, a escola e a empresa. Porto Alegre: Artmed.

Lima, E. R., \& Ramos, S. G. (2002). A presença dos pais na orientação profissional. In R. S. Levenfus, \& D. H. P. Soares. Orientação vocacional ocupacional: Novos achados teóricos, técnicos e instrumentais para a clínica, a escola e a empresa. Porto Alegre: Artmed.

Lisboa, M. D. (2002). Orientação Profissional e o mundo do trabalho: reflexões sobre uma nova proposta frente a um novo cenário. In R. S. Levenfus, \& D. H. P. Soares. Orientação vocacional ocupacional: Novos achados teóricos, técnicos e instrumentais para a clínica, a escola e a empresa. Porto Alegre: Artmed.

Messara, L., Mourad, M., \& Harake, N. A. (2009). The linkage between professionals' goal orientation and career anchors. International Journal of Business Research, 9(1), 50-56. Recuperado em 15 de abril, 2010, de www.encyclopedia.com/doc/1G1-18756097.html

Millan, L. R., Azevedo, R. S., Rossi, E., Marco, O. L. N. de, Millan, M. P. B., \& Arruda, P. C. V. (2005). What is behind a student's choice for becoming a doctor? Clinics, 60(2), 143-150. Recuperado em 12 de abril 2010, de http://www.scielo.br/scielo.php?script=sci_ arttext\&pid=S1807-59322005000200011\&lng=en\& nrm=iso

Nunes, E., \& Carvalho, M. M. (2006). Ensino universitário, corporação e profissão: paradoxos e dilemas brasileiros. Observatório Universitário. Databrasil Ensino e Pesquisa. Recuperado em 24 fevereiro 2008, de http://www.databrasil.org.br/Databrasil/DB_ PublicacoesDoc.htm

Peñaloza, V., Diógenes, C. G., \& Sousa, S. J. A. (2008). Escolha profissional no curso de Administração: Tendências empreendedoras e gênero. Revista de Administração Mackenzie (RAM), 9(8). Recuperado em 15 de abril, 2010, de http://www3.mackenzie. br/editora/index.php/RAM/article/view/214/214 
Porto,J.B.,\&Tamayo,A.(2006).Influênciadosvaloreslaborais dos pais sobre os valores laborais dos filhos. Psicologia Reflexão e Crítica, 19(1). Recuperado em 29 de abril, 2010, de http://www.scielo.br/scielo.php?script=sci_ arttext\&pid=S0102-79722006000100020\&lng=en\&n $\mathrm{rm}=\mathrm{iso}$

Prado, K., Filho (1993). A escolha profissional e atualidade no mercado de trabalho. In D. H. P. S. Lucchiari (Org.). Pensando e vivendo a orientação profissional. São Paulo: Summus.

Rodrigues, C. A. S., Ferraz, S. F. S., Duarte, M. F. (2008). Aposentadoria precoce e inflexão de carreira: Um estudo exploratório. Anais eletrônicos do Congresso Nacional de Excelência em Gestão, Niterói, Rio de janeiro, Brasil, 4. Recuperado em 5 de abril, 2010, de http://www.excelenciaemgestao.org/Portals/2/documents/cneg4/ anais/T7_0049_0318.pdf

Rodrigues, C. L. M. M., Bouzada, V. C. P. C., Kilimnik, Z. M. (2007). Estilo de Vida e segurança - Seriam essas as âncoras de futuros detentores de "carreiras proteanas, ou sem fronteiras"? - Um estudo comparativo entre alunos de graduação e de mestrado em Administração. Anais eletrônicos do Congresso Virtual Brasileiro, 7. Recuperado em 10 maio, 2010, de http://www.convibra.com.br/2007/congresso/artigos/160.pdf

Santos, L. M. M. (2005). O papel da família e dos pares na escolha profissional. Psicologia em Estudo, 10(1), 57-66. Recuperado em 1을 de abril, 2010, de http://www.scielo.br/scielo.php?script=sci arttext\&pid=S1413-73722005000100008\&lng=en\&n $\mathrm{rm}=\mathrm{iso}$

Schein, E. H. (1978). Career dynamics: Matching individual and organizational needs. Reading: Addison-Wesley Publishing.

Schein, E. H. (1990). Career anchors: Discovering your real values. São Francisco: Jossey-Bass/Pfeiffer.

Schein, E. H. (1996a). Career anchors revisited: implications for career development in the 21st century. Academy of Management Executive, 0(0), 80-88. Recuperado em 10 de abril, 2010, de http://www.jstor.org/pss/4165355

Schein, E. H. (1996b). Identidade profissional: Como ajustar as suas inclinações a suas opções de trabalho. São Paulo: Nobel.

Schein, E. H. (2006a). Career anchors: Facilitator's guide (3. ed.). São Francisco: Pfeiffer.
Schein, E. H. (2006b). Career anchors: Self-assessment (3. ed.). São Francisco: Pfeiffer.

Schein, E. H. (2006c). Career anchors: Participant workbook (3. ed.). São Francisco: Pfeiffer.

Sennett, R. (2002). A corrosão do caráter: Consequências pessoais do trabalho no novo capitalismo. Rio de Janeiro: Record.

Silva, I. C. T., \& Birk, C. (2002). Um modelo de atendimento em orientação profissional na escola privada. In R. S. Levenfus, \& D. H. P. Soares. Orientação vocacional ocupacional: Novos achados teóricos, técnicos e instrumentais para a clínica, a escola e a empresa. Porto Alegre: Artmed.

Soares, D. H. P. (2002). A escolha profissional: Do jovem ao adulto. São Paulo: Summus.

Soares, S. A. M. (2007). A escolha do curso de serviço social: Implicações subjetivas. Dissertação de mestrado, Pontifícia Universidade Católica de São Paulo, São Paulo.

Sobral, J. M., Gonçalves, C. M., \& Coimbra, J. L. (2009). A influência da situação profissional parental no desenvolvimento vocacional dos adolescentes. Revista Brasileira de Orientação Profissional, 10(1), 11-22. Recuperado em 29 de abril, 2010, de http://pepsic.bvs-psi.org.br/scielo.php?script=sci_ arttext\&pid=S1679-33902009000100004\&lng=pt\&nr $\mathrm{m}=\mathrm{iso}$

Sombrio, K. N. (2003). Ser professora - O sentido de uma escolha: Um estudo sobre âncoras de carreira. Dissertação de mestrado, Universidade Federal de Santa Catarina, Florianópolis.

Sparta, M., \& Gomes, W. B. (2005). A importância atribuída ao ingresso na educação superior por alunos do ensino médio. Revista Brasileira de Orientação Profissional, 6(2), 45-53. Recuperado em 12 de abril 2010, de http://pepsic.bvsalud.org/scielo.php?script=sci arttext\&pid=S1679-33902005000200005\&lng=pt\&nr $\mathrm{m}=$ iso

Teles, J., Freguglia, R., \& Carvalho, F. F. (2002). Juventude e mercado de trabalho no Rio de Janeiro e em Minas Gerais. Econômica, 4(2), 223-250. Recuperado em 16 de abril, 2010, de http://www.uff.br/revistaeconomica/v4n2/teles.pdf

Whitaker, D. (1997). Escolha de carreira e globalização (11. ed.). São Paulo: Moderna. 